\title{
The Classification of Error Correction
}

\author{
ChingChih Tsai ${ }^{1}$, JungChih Tsai ${ }^{2 *}$
}

\author{
${ }^{1}$ Department of English, Badou Senior High School, Keelung, Taiwan \\ ${ }^{2}$ School of Humanities, Minjiang University, Fuzhou, Fujian \\ ${ }^{*}$ Corresponding author. Email: jungchih99@qq.com
}

\begin{abstract}
Error correction has long been discussed in the groups of second language writing teachers. Employing document analysis to scrutinize significant research mainly from 1991 to 2018, the study aims at building a dialogue platform with the same bases for error correction teachers. Sixteen types of error correction were categorized with suggestions for future studies.
\end{abstract}

Keywords: error correction, teacher feedback, error feedback, corrective feedback, written feedback

\section{INTRODUCTION}

Error correction in second language (L2) writing has been discussed with different issues and entailed diverse labels, such as error feedback [1][2][3][4], written feedback [5], teacher feedback [6][7][8][9], error treatment [8][10], grammar correction [11][12], or corrective feedback [2][3][4][6][13][14][15][10][16][17] [18][19].

Research on error correction has revealed inspiring findings. Topics are under debate on why teachers should correct errors and how they should do it [3]. Ferris examined papers from 1982 to 2000 and suggested a systematic and longitudinal design including treatment and control groups to reach an identical conclusion before judging whether error correction works or not [10]. The situation was as Liu mentioned that it is important to investigate all kinds of error correction because one type of its method, approach, or strategy would not work for all error types [4].

I reviewed studies conducted from 1991 to 2018 and discovered that the classification of error correction is diversified and worthy of examination. Therefore, I tried to classify these discussions into three categories and offered a new framework of error correction types.

\section{DISCUSSIONS REGARDING TYPES OF ERROR CORRECTION}

These articles not only discussed different types of error correction but also the efficacy of error correction, especially the relationship between different types and effects of error correction. That is why these studies need to categorize different types of error correction.

In Kepner's study, two types of error correction were mentioned: surface error-corrections and message-related comments. The former pertained more to the level of grammatical accuracy in the L2 writing, whereas the latter focused on the level of thinking, meaning the content of writing [5].

Ashwell declared "four different patterns of teacher feedback" including content, form, both content and form feedback as well as zero feedback as a control group. For Group Content, the teacher will provide general comments, not text specific; for Group Form, all the grammar errors will be underlined [6]. No error correction will be offered to the zero feedback group, which I will not treat as one type. In addition, he also called content feedback as meaning-focused or content-focused one, form feedback as form-focused one. In both content and form feedback group, he divided students into three subgroups: content-then-form, form-then-content, and mixed content and form. On the other hand, he mentioned that form feedback can be treated as grammar correction, but a more widely name [6] (see. Table 1)

Table 1. Ashwell's five types of teacher feedback

\begin{tabular}{|l|l|l|}
\hline \multirow{4}{*}{$\begin{array}{l}\text { Teacher } \\
\text { feedback }\end{array}$} & \multicolumn{2}{|l|}{ Form feedback } \\
\cline { 2 - 3 } & Content feedback \\
\cline { 2 - 3 } & $\begin{array}{l}\text { Content and form } \\
\text { feedback }\end{array}$ & Mixed content and form feedback \\
\cline { 3 - 3 } & & Content-then-form feedback \\
\cline { 2 - 3 } & & Form-then-content feedback \\
\hline
\end{tabular}

Chandler compared four different patterns of error correction and suggested that students need to revise 
their writings after receiving their error feedback from teachers; otherwise, they would not make any progress in writing as those who did not acquire any feedback. In her experiment, she found that correct errors directly and simply underlining of errors are better ways than the other two, inclusive of pointing out types of error and types of error with underlining. In her categories, four different types are direct correction, underlining with marginal description of type of error, marginal description of type, and simple underlining, briefly named "Correction," "Underlining with Description," "Description," and "Underlining" [1].

Lee investigated L2 writing teachers' perspectives, practices, and problems regarding error feedback. She found that teachers' error correction practices focused on helping students with direct and comprehensive correction. It is not always constant with their beliefs or the published research like marking codes or selective marking for the errors. It seems that teachers do not plan to help students "learn to analyze their own errors" even most of them reaching an agreement with the belief. Besides, she mentioned another three significant issues about types of error correction: to correct students' errors or not, to identify their error types or not, and to locate those errors directly or indirectly [2].

Lee pointed out a fundamental issue that writing teachers faced whether to correct all the errors for students' writing or not. This involves comprehensive and selective error correction. Considering giving explicit error feedback or not, Lee mentioned direct and indirect error correction. In addition, she discussed the usefulness of error codes in the aspect of indirect error feedback, dividing indirect error correction into two sections: coded and uncoded ones [3].

Combining these thoughts with the error correction issues, I acquired ten types of error correction (see Table 2).

Table 2. Ten types of error correction

\begin{tabular}{|c|c|c|c|c|}
\hline & $\begin{array}{l}\text { Comprehe } \\
\text { nsive error } \\
\text { correction }\end{array}$ & $\begin{array}{l}\text { Selective } \\
\text { error } \\
\text { correction }\end{array}$ & $\begin{array}{c}\text { No error } \\
\text { correctio } \\
n\end{array}$ \\
\hline \multirow{2}{*}{$\begin{array}{l}\text { Locati } \\
\text { ng } \\
\text { errors } \\
\text { directl } \\
\text { y }\end{array}$} & Coded & Type 1 & Type 5 & Type 9 \\
\hline & $\begin{array}{l}\text { Uncod } \\
\text { ed }\end{array}$ & Type 2 & Type 6 & Type 10 \\
\hline \multirow{2}{*}{$\begin{array}{l}\text { Locati } \\
\text { ng } \\
\text { errors } \\
\text { indire } \\
\text { ctly }\end{array}$} & Coded & Type 3 & Type 7 & $\begin{array}{c}\text { meaningl } \\
\text { ess }\end{array}$ \\
\hline & $\begin{array}{l}\text { Uncod } \\
\text { ed }\end{array}$ & Type 4 & Type 8 & $\begin{array}{c}\text { meaningl } \\
\text { ess }\end{array}$ \\
\hline
\end{tabular}

In Table 2, locating errors indirectly means reminding students errors in the front or back of "that" line in the margin. Identifying error types are coding symbols designed in advance, like SV representing "subject verb agreement," VT equaling to "Verb Tense," etc. [2]. Students will be hardly find where the errors are when the teacher merely locates their errors indirectly with coding symbols, an underline, or a circle. Therefore, I treat them as meaningless types.

Due to the debating between Truscott and Ferris, Bitchener, Young, and Cameron dedicated to understanding what extend of the type of corrective feedback improved writing performance. Their study concluded that L2 writing teachers could better "cure" their learners with both oral and written feedback simultaneously. In other words, there were three types of error correction: oral, written, and combined. Oral feedback focuses on the quality and organization of their content while written feedback requires direct and explicit. The combined one will provide five-minute discussion conference between student and researcher besides written feedback [13].

\section{FOCI ON THE EFFECTS OF ERROR CORRECTION}

For the effects of error correction, researchers conducted an experimental or quasi-experimental research to measure whether significant effects can be seen on L2 writings.

In Mantello's teaching strategies, she mentioned different types of error correction inclusive of comprehensive and selective error correction, surface-level errors, coded feedback, and reformulation feedback. According to Mantello, selective feedback entails correcting "a limited number of language structure consistently and persistently over a period of time." It is called partial or limited feedback as well. Coded feedback and reformulation feedback belong to selective error correction. The prerequisite of reformulation is a native teacher to the target language partially rewriting the learners' works to make them "more native like." Opposite to surface-level feedback is the idea of a written text; i.e., content-level feedback [20] (see Table 3).

Table 3. Four types of error correction

\begin{tabular}{|c|c|c|c|}
\hline \multirow{2}{*}{$\begin{array}{c}\text { Error } \\
\text { correction }\end{array}$} & \multirow{2}{*}{ Surface-level } & Selective & Coded \\
\cline { 2 - 3 } & & \multicolumn{2}{|c|}{ Comprehensive } \\
\cline { 2 - 3 } & \multicolumn{3}{|c|}{ Content-level } \\
\hline
\end{tabular}

Liu conducted a semi-experimental study to investigate the effects on error feedback. Her research focused on the differences between direct and indirect error correction consisting of subtypes of coding (or description) and underling. She employed the same categories in the aspects of direct and indirect error correction as Chandler in 2003, Bitchener et al in 2005, and Bitchener in 2008 categorized [4].

Eslami compared the effects of two different error correction: direct and indirect. Her study was mainly on the red pen technique that teachers in Iran used most to 
give the correct form of students' writings directly with meta-linguistic explanations in some cases. In addition to direct and indirect error correction, she mentioned that one further distinction that needed examining was focused and unfocused error feedback. The former selected specific errors to correct while the latter, also named extensive error feedback, corrected all errors of students' writings [15].

Mahshhadi and Biria's investigation found that teachers were able to reduce students' L2 writing errors by providing full, explicit, and coded written feedback accompanied with oral instruction contrast to the other treatment group: doing error correction exercise on their own or consulting with their peers, and the control group receiving only content feedback. In their research, they tried to understand the efficacy of different types of error correction. They also mentioned that there were unanswered questions - which type of error feedback is more effective, direct and indirect, coded and uncoded, or delayed and undelayed? I think that delayed or undelayed error feedback pertains to time, not types. Despite Mahshhadi and Biria tested three groups of error correction, it seemed that there were more types of error correction when we considered the different dimensions mentioned above [9].

Tanveer, Malghani, Khosa, and Khosa applied quantitative research design to investigate the effectiveness of written feedback. They analyzed types of written corrective feedback before conducting its effectiveness [9]. Those types including oral and written, direct and indirect, located and non-located, and reformulation ones have all been discussed above.

I synthesized these error correction into 16 types (see Table 4).

Table 4. Sixteen types of error correction

\begin{tabular}{|c|c|c|c|c|c|}
\hline & & \multicolumn{2}{|c|}{ Written } & \multicolumn{2}{c|}{ Oral } \\
\hline & & Full & Partial & Full & Partial \\
\hline \multirow{2}{*}{ Explicit } & Coded & Type 1 & Type 5 & Type 9 & Type 13 \\
\cline { 2 - 6 } & Uncoded & Type 2 & Type 6 & Type 10 & Type 14 \\
\hline \multirow{2}{*}{ Implicit } & Coded & Type 3 & Type 7 & Type 11 & Type 15 \\
\cline { 2 - 6 } & Uncoded & Type 4 & Type 8 & Type 12 & Type 16 \\
\hline
\end{tabular}

In Table 4, "Full" is comprehensive error correction, "Partial" indicates selective, "Explicit" is to locate errors directly while "Implicit" points out to locate errors indirectly.

How do teachers practice Type 15 and Type 16? Do they exist? In my cases, oral feedback always comes after the written ones. When there are too many errors in one student's first writing draft, I will cease to make any full, explicit, and coded error feedback after I finish examining the student's first or first two paragraphs. Then I will give the following parts a big brace or a separate line from the above and tell my student: "There are a lot of mistakes in it. Please check out what I've corrected for you, rewrite, and hand in your second draft." This is Type 16. If I add a few words like "especially your verb tense, and the agreement between your subject and verb," it belongs to Type 15 .

\section{ARGUMENTATIONS OVER THE NECESSITY OF ERROR CORRECTION}

Whether error correction is effective or not had been an issue for more than 15 years before Truscott declared that instructors should abandon error or grammar correction because it was helpless and had severe harmfulness to L2 learners in both aspects of theory and practice. It seemed that he only treated error correction as one type - grammar correction. He, however, cited and discussed four categories of error correction from Semke's study in 1984, containing only comments on content, only comments on errors, both types (content and errors) of comments, and having errors pointed out with self-correction expectations [11].

Hyland \& Hyland examined the literature and found that feedback plays one of the most important roles in L2 writing; nonetheless, it did not show the completely positive function to L2 learners. This article discussed four categories of feedback comprehensively, which are written feedback, oral feedback, collaborative peer feedback, and computer-mediated feedback consisting of synchronous and asynchronous computer-mediated communication (CMC), automated feedback from the software, and corpora-based feedback (see Table 5) [7].

Table 5. Seven types of feedback

\begin{tabular}{|c|c|c|}
\hline \multirow{7}{*}{$\begin{array}{l}\text { Types of } \\
\text { Feedback }\end{array}$} & \multicolumn{2}{|c|}{ Teacher written feedback } \\
\hline & \multicolumn{2}{|c|}{ Teacher oral feedback } \\
\hline & \multicolumn{2}{|c|}{ Collaborative peer feedback } \\
\hline & \multirow{4}{*}{$\begin{array}{c}\text { Computer-mediated } \\
\text { feedback }\end{array}$} & Synchronous CMC \\
\hline & & Asynchronous CMC \\
\hline & & $\begin{array}{c}\text { Automated } \\
\text { feedback }\end{array}$ \\
\hline & & $\begin{array}{c}\text { Corpora-based } \\
\text { feedback }\end{array}$ \\
\hline
\end{tabular}

Guénette reviewed the literature and found that the contradictory conclusions on correction feedback came from the different variables to consider among the authors; i.e., different types of feedback, designs, procedures, even definition to proficiency level, etc. The author suggested these findings originating from different research designs, methodologies, and controlled variables can be reminders for future studies. In the study, she induced three types of error correction: feedback on form, on content, and on both. Feedback on form consists of direct and indirect feedback. Indirect feedback consisted of six subtypes in her study [16]. In sum, nine types of error correction were generalized (see Table 6). 
Table 6. Nine types of error treatments

\begin{tabular}{|c|c|c|c|}
\hline & & & ct feedback \\
\hline & & & Errors coded \\
\hline & & & Errors circled \\
\hline & & & Errors underlined \\
\hline & & & $\begin{array}{l}\text { Errors underlined } \\
\text { and coded }\end{array}$ \\
\hline Treatments $^{1}$ & $\begin{array}{l}\text { Feedback } \\
\text { on form }\end{array}$ & $\begin{array}{c}\text { Indirect } \\
\text { feedback }\end{array}$ & $\begin{array}{l}\text { Errors underlined } \\
\text { with description } \\
\text { of errors }\end{array}$ \\
\hline & & & $\begin{array}{l}\text { Errors counted in } \\
\text { the margin, but } \\
\text { neither marked } \\
\text { nor coded }\end{array}$ \\
\hline & & eedback o & content \\
\hline & Fee & ack on for & and content \\
\hline
\end{tabular}

Note: 1. Treatments were types of error correction in Guénette's article.

Investigating students' reactions to teacher's feedback, Lee talked about four types of error correction from the literature: teacher feedback, audio feedback, peer evaluation, and self-evaluation. However, her research focused on teachers' written feedback, which are error feedback and comments. Comments were subdivided into content, accuracy, organization, and others. In addition, her feedback strategies seem to be mixing studies of direct feedback and indirect feedback together (see Figure 1) [8].

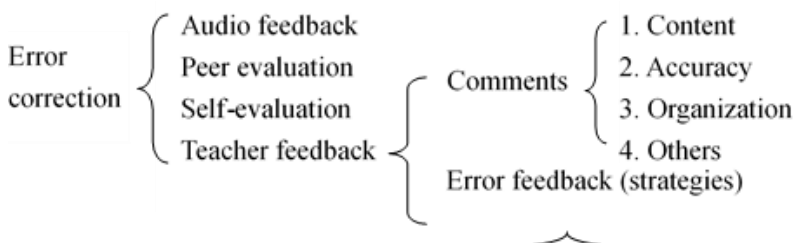

1. Underline/ circle the errors

2. Underline/ circle the errors/ and provide corrections

3. Underline/ circle and categorize the errors

4. Underline/ circle, categorize the errors, and provide corrections

5. A marked error hint in the margin

6. A categorized error hint in the margin

Figure 1 Ten types of error feedback

Bitchener analyzed papers from 1982 to 2001 and concluded a number of types of error correction and found in a variety of terms about error correction that appeared in the papers. He used corrective feedback to generalize those terms and treated them as direct and indirect feedback. The former error feedback encompasses form, written meta-linguistic, oral meta-linguistic (a mini-lesson), and one-on-one conference between teacher and student or between teacher and a small group. The latter, indirect error feedback consists of three parts: underlining or circling the error, recording the number of errors in the margin, and using an error code to locate the error and show its type (see Table 7) [14].
Table 7. Six types of corrective feedback

\begin{tabular}{|c|c|c|c|}
\hline \multirow{7}{*}{$\begin{array}{l}\text { Correcti } \\
\text { ve } \\
\text { feedba } \\
\text { ck }\end{array}$} & \multirow{4}{*}{ Direct } & \multirow{2}{*}{$\begin{array}{c}\text { Writte } \\
n\end{array}$} & Form or structure \\
\hline & & & Written meta-linquistic \\
\hline & & \multirow{2}{*}{ Oral } & Oral meta-linguistic \\
\hline & & & One-on-one conference \\
\hline & \multirow{3}{*}{$\begin{array}{c}\text { Indire } \\
\text { ct }\end{array}$} & \multirow{3}{*}{$\begin{array}{c}\text { Writte } \\
\mathrm{n}\end{array}$} & $\begin{array}{l}\text { Underlining or circling the } \\
\text { error }\end{array}$ \\
\hline & & & $\begin{array}{l}\text { Recording the number of } \\
\text { error in the margin }\end{array}$ \\
\hline & & & $\begin{array}{l}\text { Using a code to locate } \\
\text { the error and show its } \\
\text { type }\end{array}$ \\
\hline
\end{tabular}

Ferris mentioned that when researchers focused on whether the correct-all-the-errors approach, there were two types of error correction: comprehensive and selective written corrective feedback. In the light of teachers' time and energy, the types of error correction were direct and indirect. Direct error correction usually accompanies oral or written explanations [10]. When we take the level of explicitness into consideration, two subtypes of indirect error correction are more explicit and less explicit (see Table 8).

Table 8. Eight types or written corrective feedback

\begin{tabular}{|c|c|c|c|}
\hline & & Comprehensive & Selective \\
\hline \multirow{3}{*}{ Direct } & $\begin{array}{c}\text { With oral } \\
\text { explanation }\end{array}$ & Type 1 & Type 5 \\
\cline { 2 - 4 } & $\begin{array}{c}\text { With written } \\
\text { explanation }\end{array}$ & Type 2 & Type 6 \\
\hline \multirow{2}{*}{ Indirect } & More explicit & Type 3 & Type 7 \\
\cline { 2 - 4 } & Less explicit & Type 4 & Type 8 \\
\hline
\end{tabular}

In Table 8, we may regard more explicit as coded feedback, less explicit as uncoded one. According to Table 7 and Table 8, the focuses of direct error feedback are not coded or uncoded but the following written and oral explanation.

According to one of teachers' continuously asked questions: Why bother to do error feedback if students do not seem to be improving? Evans, Hartshorn, McCollum, and Wolfersberger appealed to a paradigm change, providing a new type or subtype of error correction called dynamic written corrective feedback (WCF). In their new paradigm, teachers only focused on how to improve students' L2 writing instead of asking whether they should provide WCF or not. WCF is based on the subsequent two teaching principles: (1) Feedback is what the individual learner needs most, and (2) Feedback and next task should be "manageable, meaningful, timely, and constant" for the learner and the teacher [17].

Livingstone simply discriminated error correction between oral and written forms. In addition, he reviewed Hendrickson's five questions about error question in 1978 and briefly expressed his own viewpoints on them. Arguments over which errors to correct, there will be specific and comprehensive types of error correction. Discussing the way to correct L2 writing errors, we will 
have written and oral feedback. The latter including implicit and explicit treatments. As to the issue on whom to correct errors, teachers' error feedback is thought to be the most important although peers' feedback, self-correction as well as error correction of the teacher and the student are all considered (see Figure 2) [18].

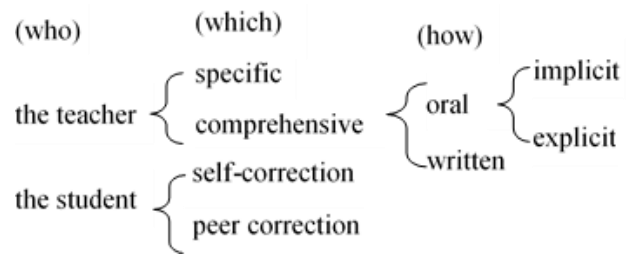

Figure 2 Sketch of error correction

Because Livingstone's research was on students' and teachers' perception of error correction and its strategies, different types of error correction seemed incomplete. I, nevertheless, tried to classify them into eight types of teachers' error correction except for those involved in students self-correction or peer correction (see Table 9) [18].

Table 9. Eight Types of Error Correction

\begin{tabular}{|c|c|c|c|}
\hline & & Comprehensive & Specific \\
\hline \multirow{2}{*}{ Explicit } & oral & Type 1 & Type 5 \\
\cline { 2 - 4 } & written & Type 2 & Type 6 \\
\hline \multirow{2}{*}{ Implicit } & oral & Type 3 & Type 7 \\
\cline { 2 - 4 } & written & Type 4 & Type 8 \\
\hline
\end{tabular}

Synthesizing what I have mentioned above, I found the focus of error correction has apparently changed. Researchers are more interested in which type is better to improve students' writings than whether error correction is effective. Moreover, the dimensions underlying the written corrective feedback are originally direct or indirect, comprehensive or selective, and coded or uncoded. Adding the following oral or written comments to the original dimensions is inevitably essential. As to those underlining, circling, or specific marks, they unquestionably belong to subdivisions. Therefore, one complete framework to the classification of error correction can not only be used to scrutinize what research has been implemented but also show the direction for future studies (see Table 10).

Table 10. The classification of teacher feedback

\begin{tabular}{|c|c|}
\hline $\begin{array}{c}\text { Type } \\
1\end{array}$ & $\begin{array}{l}\text { Comprehensive, direct, coded, and written } \\
\text { comments }\end{array}$ \\
\hline $\begin{array}{c}\text { Type } \\
2\end{array}$ & $\begin{array}{l}\text { Comprehensive, direct, uncoded, and written } \\
\text { comments }\end{array}$ \\
\hline $\begin{array}{c}\text { Type } \\
3\end{array}$ & $\begin{array}{l}\text { Comprehensive, indirect, coded, and written } \\
\text { comments }\end{array}$ \\
\hline $\begin{array}{l}\text { Type } \\
4\end{array}$ & $\begin{array}{l}\text { Comprehensive, indirect, uncoded, and written } \\
\text { comments }\end{array}$ \\
\hline $\begin{array}{l}\text { Type } \\
5\end{array}$ & Selective, direct, coded, and written comments \\
\hline $\begin{array}{l}\text { Type } \\
6\end{array}$ & $\begin{array}{l}\text { Selective, direct, uncoded, and written } \\
\text { comments }\end{array}$ \\
\hline Type & Selective, indirect, coded, and written \\
\hline
\end{tabular}

\begin{tabular}{|c|l|}
\hline 7 & comments \\
\hline Type & Selective, indirect, uncoded, and written \\
8 & comments \\
\hline Type & Comprehensive, direct, coded, and oral \\
9 & comments \\
\hline Type & Comprehensive, direct, uncoded, and oral \\
10 & comments \\
\hline Type & Comprehensive, indirect, coded, and oral \\
11 & comments \\
\hline Type & Comprehensive, indirect, uncoded, and oral \\
12 & comments \\
\hline Type & Selective, direct, coded, and oral comments \\
13 & \\
\hline Type & Selective, direct, uncoded, and oral comments \\
14 & \\
\hline Type & Selective, indirect, coded, and oral comments \\
15 & \\
\hline Type & Selective, indirect, uncoded, and oral \\
16 & comments \\
\hline
\end{tabular}

\section{CONCLUSION}

The study is a preliminary pertaining to integrating the classification of error correction. I chose the broadest term - error correction [12] - as a starter although I ought to conclude it at what learners' expected the best teacher feedback [8]. In addition, peer feedback, self-correction, audio feedback, and computer-mediated feedback could be the topics of future research. Table 10 displayed 16 types of teachers feedback; however, there will be more than 16 types if we add any one type to another, not to mention considering those subdivisions such as underlying, circling, and marking. This is an obvious limitation of this paper - an endless categorizing job; therefore, I induced the framework, constructing a platform for further discussion based on the analytical consensuses of these articles. Future studies could compare different types to assure that which type or types will provide the maximum benefits to writing teachers and learners.

\section{REFERENCES}

[1] J. Chandler, "The efficacy of various kinds of error feedback for improvement in the accuracy and fluency of L2 student writing," Journal of second language writing, 12(3) (2003) 267-296. DOI: https://doi.org/10.1016/S1060-3743(03)00038-9

[2] I. Lee, "L2 writing teachers' perspectives, practices, and problems regarding error feedback," Assessing Writing 8(3) (2003) 216-237. DOI: https://doi.org/10.1016/j.asw.2003.08.002

[3] I. Lee, "Error correction in L2 secondary writing classrooms: The case of Hong Kong," Journal of second language writing, 13(4) (2004) 285-312. DOI: https://doi.org/10.1016/j.jslw.2004.08.001

[4] Y. Liu, "The effects of error feedback in second language writing," Journal of Second Language 
Acquisition and Teaching, 15 (2008) 65-79. https://journals.uair.arizona.edu/index.php/AZSLA T/article/view/21254/20834

[5] C. G. Kepner, "An experiment in the relationship of types of written feedback to the development of second-language writing skills," The modern language journal, 75(3) (1991) 305-313. DOI: https://doi.org/10.2307/328724

[6] T. Ashwell, "Patterns of teacher response to student writing in a multiple-draft composition classroom: Is content feedback followed by form feedback the best method?" Journal of second language writing, 9(3) (2000) 227-257. DOI: https://doi.org/10.1016/S1060-3743(00)00027-8

[7] K. Hyland and F. Hyland, "Feedback on second language students' writing," Language teaching, 39(2) (2006) 83-101. DOI: https://doi.org/10.1017/S0261444806003399

[8] I. Lee, "Student reactions to teacher feedback in two Hong Kong secondary classrooms," Journal of second language writing, 17(3) (2008) 144-164. DOI: https://doi.org/10.1016/j.jslw.2007.12.001

[9] F. Mashadi and R. Biria, "Error Is Not Terror: Error Correction in Second Language Writing," Journal of Applied Linguistics and Language Research, vol. 3, no. 6, pp. 199-212, October 2016.

[10]D. R. Ferris, "Second language writing research and written corrective feedback in SLA: Intersections and practical applications," Studies in Second Language Acquisition, 32(2) (2010) 181-201.

DOI: https://doi.org/10.1017/S0272263109990490

[11] J. Truscott, "The case against grammar correction in L2 writing classes," Language learning, 46(2) (1996) 327-369. DOI: https://doi.org/10.1111/j.1467-1770.1996.tb01238. $\mathrm{x}$

[12] J. Truscott, "The effect of error correction on learners' ability to write accurately," Journal of second language writing, 16(4) (2007) 255-272. DOI: https://doi.org/10.1016/j.jslw.2007.06.003

[13] J. Bitchener, S. Young, and D. Cameron, "The effect of different types of corrective feedback on ESL student writing," Journal of second language writing, 14(3) (2005) 191-205. DOI: https://doi.org/10.1016/j.jslw.2005.08.001

[14] J. Bitchener, "Evidence in support of written corrective feedback," Journal of second language writing, 17(2) (2008) 102-118. DOI: https://doi.org/10.1016/j.jslw.2007.11.004
[15]E. Eslami, "The effects of direct and indirect corrective feedback techniques on EFL students' writing." Procedia-Social and Behavioral Sciences, 98 (2014) 445-452. DOI: https://doi.org/10.1016/j.sbspro.2014.03.438

[16]D. Guenette, "Is feedback pedagogically correct? Research design issues in studies of feedback on writing," Journal of second language writing, 16(1) (2007) 40-53. DOI: https://doi.org/10.1016/j.jslw.2007.01.001

[17] N. W. Evans, K. J. Hartshorn, R. M. McCollum, and M. Wolfersberger, "Contextualizing corrective feedback in second language writing pedagogy," Language Teaching Research, 14(4) (2010) 445-463.

DOI: https://doi.org/10.1177/1362168810375367

[18]K. A. Livingstone, "Correcting errors in the L2 classroom: students' and teachers' perceptions," Revista Electrónica del Lenguaje, 2 (2015) 1-36. https://www.researchgate.net/publication/2788474 83_Correcting_errors_in_the_L2_classroom_stude nts'_and_teachers'_perceptions

[19]A. Tanveer, M. Malghani, D. Khosa, and M. Khosa, "Efficacy of Written Corrective Feedback as a Tool to Reduce Learners' Errors on L2 Writing," International journal of English linguistics, 8(5) (2018) 166-180. DOI: : https://doi.org/10.5539/ijel.v8n5p166

[20]M. Mantello, "Error correction in the L2 classroom," Canadian modern language review, 54(1) (1997) 127-131. DOI: https://doi.org/10.3138/cmlr.54.1.127 